\title{
“HUNGRÍA MÁRTIR" - EL NOTICIARIO ESPAÑOL Y LA REVOLUCIÓN HÚNGARA DE 1956
}

\section{BENCE GERGő PaTKós}

Universidad de Szeged, Hungría

\begin{abstract}
Resumen: Uno de los acontecimientos más destacados de la historia de Hungría en el siglo XX fue la revolución de 1956, cuya repercusión internacional fue considerable también. En este ensayo intento contestar a la pregunta sobre cómo el NO-DO (Noticiarios y Documentales) de la España franquista, uno de los instrumentos de propaganda más importantes del régimen, representaba los sucesos revolucionarios que se estaban desarrollando en Hungría. En primer lugar, voy a presentar el contexto histórico de Hungría y España y sus relaciones diplomáticas, luego el carácter de la propaganda y del noticiario en España. En la segunda parte del ensayo, mediante el análisis de los noticiarios accesibles en un archivo digitalizado en Internet, expongo la repercusión española de la revolución a través de los noticiarios e intento explicar por qué era útil la revolución para el gobierno español en su propaganda.
\end{abstract}

Palabras clave: revolución húngara de 1956, propaganda franquista, noticiario.

Abstract: The revolution of 1956 was one of the most significant events in the history of Hungary during the 20th century. In the present study, I am discussing how the newsreel of the Francoist Spain (Noticiarios y Documentales, NO-DO), being one of the most crucial instruments of the regime's propaganda, portrayed the revolutionary events in Hungary. First, I will introduce the historical background and relations between the two countries, I will explain briefly the notion of propaganda, and the role of the newsreel in Spain. Later, I will examine the echo of the Hungarian revolution in Spain based on the analysis of digitalized newsreels accessed through Internet. Moreover, I will aim to provide an answer as to why did the revolution have a key role in the Spanish government's propaganda.

Keywords: Hungarian Revolution of 1956, Francoist Propaganda, Newsreel.

\section{E1 contexto histórico}

\subsection{Hungría en los años 50 y la revolución de 1956}

Después de la Segunda Guerra Mundial, Hungría, tras la ocupación soviética en 1945, pertenecía a la esfera de influencia de la Unión Soviética y se llevó a cabo la sovietización del país tanto en el terreno político como en el económico lo que trajo consigo la adopción del sistema comunista conocido de la URSS. Después de un corto período democrático entre 1945 y 1948, el Partido de los Trabajadores Húngaros (fruto de la fusión del Partido Comunista Húngaro y del Partido Socialdemócrata), como único partido de la época, tomó el mando del estado y con el liderazgo de Mátyás Rákosi, Hungría se convirtió en una dictadura unipartidista. Nació un sistema totalitario 
cuyo líder incuestionable y paternalista fue Mátyás Rákosi, "el mejor alumno de Stalin" (Romsics, 2005: 294-296).

Durante la era de Rákosi se produjo la nacionalización de las grandes fábricas, la industrialización del país (sobre todo con el desarrollo de la industria pesada), la colectivización de las tierras (creando los koljoses) e incluso introdujeron los planes quinquenales económicos con el fin de dominar e influir en todos los sectores de la economía, trastornando así la economía húngara y provocando graves daños en ella. Por consiguiente, el nivel de vida disminuyó a pasos agigantados. A la vez, con el fin de divulgar la ideología comunista, nacionalizaron la enseñanza y para impedir la expansión de otras ideas tomaron medidas antieclesiásticas y limitaron las libertades de prensa y de pensamiento. En estos años se llevaron a cabo las purgas políticas también contra representantes de la oposición (por ejemplo, contra József Mindszenty, el cardenal húngaro que aparecerá en el noticiario español también o contra Béla Kovács, político del Partido Independiente Cívico de los Pequeños Propietarios y de los Trabajadores Agrarios) y contra políticos del mismo Partido de Trabajadores Húngaros, entre ellos contra László Rajk -participante en la Guerra Civil Española- que fue una de las figuras más prominentes y populares del partido y por consiguiente, fue rival de Rákosi. Este terror alcanzó también a la sociedad civil: miles de personas fueron víctimas del trabajo forzoso en los campos de internamiento o fueron encarceladas y torturadas, incluso ejecutadas en las cárceles de la policía política, llamada ÁVO (Államvédelmi Osatály Departamento de Protección del Estado), luego ÁH (Államvédelmi Hatóság - Autoridad de Protección del Estado) (Romsics, 2005: 343-350, 359).

Sin embargo, tras la muerte de Stalin en 1953, Nikita Jrushchov pudo reforzar su poder en el Partido Comunista de la Unión Soviética (PCUS), y tanto allí como en sus países satélites, entre ellos Hungría, en los años siguientes se experimentó la distensión de la dictadura. Invitaron a Rákosi a Moscú y allí le reprendieron por la industrialización, por el culto a la personalidad, por el terror, etc. Por las críticas frente a él, se destituyó al dictador húngaro de su cargo y nombraron a Imre Nagy como primer ministro de Hungría (1953-1955). Durante su gobierno frenaron la industrialización fuerte de la economía, apoyaron más la agricultura, pararon la oleada de terror y la vida cultural no se gestionó desde el punto de vista ideológico. Al mismo tiempo, Rákosi siempre intentaba recuperar su poder. En 1955 los líderes políticos de la URSS invitaron a Nagy a Moscú y allí criticaron su actividad que se consideraba extremamente reformista. Aprovechando esta situación, Rákosi comenzó a atacar a Nagy y logró que le destituyesen y expulsasen del partido, y consiguió también que nombrasen a un político a la cabeza de Hungría que era su títere. Tras la destitución de Nagy empezó la restalinización del país volviéndose a tomar medidas parecidas a las de la era Rákosi: aumentaba el ritmo de industrialización, crecía el terror, etc. Pero en el XX Congreso del PCUS, Jrushchov en su discurso secreto atacó firmemente el culto a la personalidad de Stalin y de los otros políticos del bloque y criticó las violaciones de la ley. Mediante este discurso aceptó el comienzo de la desestalinización y también legitimó la política 
reformista de Imre Nagy. Entre estas circunstancias tensas se destituyó a Rákosi de nuevo de su cargo y tuvo que emigrar del país a la Unión Soviética. Desde allí, pese a sus intentos, nunca pudo volver a Hungría. Tras la destitución de Rákosi, el sistema otra vez comenzó un proceso de distensión en Hungría y se intensificaron las voces críticas del régimen (Romsics, 2005: 376-377, 379-384).

La primera gran manifestación de los críticos contra el sistema fue el 6 de octubre de 1956 cuando volvieron a enterrar a László Rajk y el 13 de octubre Imre Nagy fue rehabilitado. La chispa de la revolución fue la reunión de los estudiantes de la Universidad de Szeged cuando los jóvenes universitarios reorganizaron la MEFESZ (Magyar Egyetemi és Föiskolai Egyesületek Szövetsége - Alianza de Asociaciones Universitarias y de Escuelas Superiores), una alianza que se distinguía del sindicato universitario estatal y juvenil comunista DISZ (Dolgozó Ifjúság Szövetsége - Alianza de la Juventud Trabajadora). Los estudiantes de las otras universidades siguieron el ejemplo de los de Szeged y luego, con el liderazgo de los estudiantes de la Universidad Politécnica de Budapest organizaron una manifestación para el día 23 que simpatizaba con las reformas iniciadas en Polonia y que quería lograr las reivindicaciones políticassociales de los estudiantes. De esta manifestación se desarrollaron la revolución y los combates en las calles de Budapest y en otras importantes ciudades húngaras. Los acontecimientos duraron hasta el 4 de noviembre cuando las tropas soviéticas derrotaron la revolución y la insurrección. Después de la revolución, cien mil personas emigraron del país, miles fueron encarcelados o ejecutados (entre ellos Imre Nagy, el primer ministro de la revolución) y János Kádár se convirtió en el dictador de Hungría hasta 1988. A pesar de la derrota, la revolución tuvo un enorme impacto sobre el futuro de la política en el país (Romsics, 2005: 387-397).

\subsection{España en los años 50}

Tras la Guerra Civil Española, Francisco Franco introdujo un régimen claramente dictatorial, un estado totalitario, en el cual todo el poder (sobre todo el poder legislativo y ejecutivo) se concentraba en sus manos. Tanto en el terreno político como en el económico y social, el gobierno tuvo que estabilizar el estado a causa de la crisis política y económica, consecuencias de la guerra fratricida. Sin embargo, el aislamiento político exterior dificultaba mucho la consolidación del país, por lo que se instauró la política autárquica y el estado intervino en los procesos económicos. Pese a los intentos, la economía no pudo recuperarse plenamente y empezó la erosión del sistema a comienzos de los años 50 (Anderle, 2002: 150-152).

Esta erosión se manifestó en 1956 cuando el estado se encontraba en una cierta crisis política y económica que provocó el descontento de la sociedad. Éste desencadenó manifestaciones y huelgas universitarias, sobre todo en la capital. En febrero de 1956 los estudiantes de la Universidad de Madrid se enfrentaron al Sindicato Español Universitario (SEU), cuestionando su razón de ser como único representante 
de los universitarios, y propusieron la institución del Congreso Libre de Estudiantes con el fin de desmontar el SEU. Los estudiantes organizaron una manifestación pacífica que desembocó en enfrentamientos violentos en las calles de Madrid. Los conflictos universitarios, que duraron unos diez días, trajeron consigo el nacimiento de una nueva oposición compuesta de jóvenes e intelectuales. Entre los protagonistas podemos encontrar a los hijos del régimen, los antiguos falangistas o hijos de prohombres del régimen. Con el propósito de terminar con la crisis universitaria, el gobierno introdujo el estado de excepción e hizo un reajuste gubernamental, destituyendo a varias figuras prominentes de la política española. Estos procesos políticos culminaron en el cambio de gobierno el 25 de febrero de 1957 (Martínez, 1999: 106-107; Tamares, 1988: 189190; Zalai, 2017: 104-105). Aparte de los movimientos universitarios, hay que mencionar que se convocaron manifestaciones obreras también, ya que en la primavera del mismo año, debido a sus dificultades, estalló una cadena de huelgas en las zonas industrializadas septentrionales (Asturias y País Vasco) y en Cataluña también (Martínez, 1999: 109; Tamares, 1956: 190).

En cuanto a la política exterior española, podemos afirmar que después de la Segunda Guerra Mundial el país vivía en aislamiento. Sin embargo, el presidente estadounidense Truman admitió que, pese a que no simpatizaba ni con Franco ni con su régimen, necesitaba la participación de España y del dictador anticomunista en el mundo bipolar de la Guerra Fría. Debido a este reconocimiento, las relaciones estadounidense-españolas se aliviaron. Este proceso culminó en la admisión de España en la Organización de las Naciones Unidas (ONU) y en la visita del presidente Eisenhower en España. Otro evento importante de la política exterior española de 1956 que debemos destacar es cuando en la primavera de este año España desistió de su protectorado en las zonas septentrionales de Marruecos, salvo las ciudades autónomas de Ceuta y Melilla (Eiroa San Francisco, 2007: 8-12; Zalai, 2017: 103-104).

\subsection{Relaciones húngaro-españolas en los 50}

Como consecuencia de la estancia de los soldados del Ejército Rojo en Hungría, comenzaron procesos políticos y sociales que dieron como resultado la influencia crucial del partido comunista. Debido a este hecho, después de la Segunda Guerra Mundial, como condena internacional contra la España franquista, el 25 de abril Hungría rompió las relaciones oficiales con el país ibérico. Esto trajo consigo el cierre de sus representaciones diplomáticas, la expulsión de su personal y la vuelta de los embajadores acreditados en la zona, y así las relaciones permanecieron suspendidas. No obstante, los gobiernos húngaros, tanto democráticos como comunistas, buscaron el contacto con el Gobierno de la República Española que funcionaba en el exilio, incluso lo reconocieron el 22 de agosto de 1946. Al mismo tiempo, el gobierno de Franco permitió que la Legación Real de Hungría en Madrid, dirigida por Ferenc Marosy, siguiera su actividad. Esta legación en la capital española servía los intereses de Hungría 
y de los húngaros (por ejemplo, con la expedición de pasaportes válidos para los países occidentales) hasta 1969 (Anderle, 2009: 142, 155; Eiroa San Francisco, 2001: 78-79, 109-110).

Aparte de Marosy, Otto de Habsburgo también representaba a Hungría en España en esta época. El heredero del trono húngaro llegó a Madrid en diciembre de 1948 y tenía buena relación con Francisco Franco. Debido a la actividad diplomática de Marosy y de Otto de Habsburgo, fue posible que en España hubiera emisiones en húngaro en la Radio Nacional de España, gestionaran asuntos oficiales (reconocimiento de la nacionalidad, convalidación de títulos universitarios y traducciones, matrimonios, herencias, etc.) y que el país ibérico ayudara a Hungría en la revolución de 1956. Según las memorias de Marosy, Franco, guiado por la idea del anticomunismo, convocó un Consejo de Ministros, donde decidió enviar un ejército de voluntarios a Hungría. Además, ordenó que mandaran armamento, equipo y munición suficientes con aviones americanos para poder llevarlos a Sopron, Hungría (la necesidad de aviones americanos era importante, ya que los españoles no disponían de aviones que hubieran podido volar directamente de Madrid a Hungría). Sin embargo, este proyecto no se realizó por la actitud estadounidense, ya que los EE.UU. no querían intervenir en los acontecimientos de Budapest, por lo que no aprobaron la cesión de aviones (Anderle, 2009: 155-156, Eiroa San Francisco, 2001: 112-113).

España apoyó la revolución también en la Organización de las Naciones Unidas. Justamente el estado ibérico fue el primero en dirigirse al Secretariado de las Naciones Unidas sobre la cuestión húngara cuando apenas habían llegado noticias de protesta contra lo que estaba ocurriendo en Hungría y este hecho hizo que los diplomáticos españoles estuvieran orgullosos. José Félix de Lequerica, representante de España en la ONU, dijo que esto era posible porque según él, España ya conocía una buena parte de los procedimientos. A España le había servido de ensayo lo ocurrido entre 1936 y 1939. En sus discursos condenaba la entrada violenta de las tropas soviéticas en Hungría y según él, este hecho fue un acontecimiento parecido al involucramiento de las Brigadas Internacionales en la Guerra Civil Española para ayudar a los republicanos (Ferrero Blanco, 2002: 350-353).

Aparte del apoyo político, tenemos que mencionar el apoyo civil también. Celebraban misas por Hungría, emprendían acciones de ayuda y de recogida de donaciones organizadas por la Cruz Roja de España. La prensa y los órganos estatales también respaldaron a los sublevados y mostraron gran solidaridad con Hungría con el fin de demostrar y enfatizar que España pertenecía al Occidente anticomunista. No obstante, al terminar los combates en Budapest, la prensa española se dirigió al tema del fútbol y de la situación de los futbolistas húngaros tras la revolución (Anderle, 2009: 158, 163-164).

El Gobierno Republicano Español en exilio también apoyaba la revolución húngara de 1956. Ellos llamaron la atención sobre el hecho de que España sufría una dictadura, enfatizando así el carácter parecido del sistema totalitario franquista y el soviético. Los 
“Hungría mártir" - el noticiario español y la revolución húngara de 1956

representantes del Gobierno Republicano en exilio compilaron una lista de propuestas detalladas en cuanto al futuro de Hungría (pidieron la garantía de las libertades principales y de los derechos políticos, reclamaron la retirada de las tropas soviéticas y reivindicaron la pluralidad política). Esta propuesta se envió a los medios más importantes de la prensa y a políticos y figuras notables de la época (por ejemplo, Churchill, De Gaulle, Sartre, etc.) (Anderle, 2009: 164-165).

Como veremos más abajo, el gobierno español trataba el tema de la revolución húngara en uno de los medios de propaganda más importantes de la dictadura, en el noticiario español, y en él intentaba ofrecer respaldo a los revolucionarios. Antes de presentar cómo era la imagen de la revolución húngara en el noticiario, tenemos que aclarar el concepto de propaganda y contestar a la pregunta: ¿cómo encajaba el noticiario español en ella?

\section{La propaganda y el NO-DO (Noticiarios y Documentales)}

La propaganda es la divulgación institucional de una ideología, de una idea mediante varios instrumentos comunicativos, cuyo objetivo es difundir los éxitos del gobierno y, a través de ello, la justificación de sí mismo. Los principales canales de la propaganda por medio de los cuales se puede influir y convencer a la sociedad de los hechos justificados del poder son el mismo gobierno, la iglesia, los órganos científicos, el sistema educativo, el arte, la prensa, otras organizaciones sociales, etc. La persuasión del público, como objetivo más importante de la propaganda, se puede realizar profesando los éxitos y ocultando los fracasos o imputándolos a los enemigos exteriores e interiores del poder. Los principales métodos de la persuasión de la sociedad son un mensaje simple y fácil de entender, la exageración, la transfusión (o sea, las principales intersecciones donde el mensaje puede ser transmitido al receptor, por ejemplo, referencias a eventos históricos, costumbres nacionales, etc.) y, en cuanto a los canales audiovisuales, como el noticiario, la instrumentación de los mensajes, ya que la imagen y el audio juntos impactan a los espectadores (Lénárt, 2018: 36-40; Virányi, 2019: 4-5; Zeidler, 2012: 7-8).

Como el cine ofrecía una diversión barata, fácil de acceder y no necesitaba el conocimiento de lectura o escritura, podía alcanzar a grandes masas de la sociedad. Reconociendo esto, el NO-DO (Noticiarios y Documentales) pronto se convirtió en uno de los instrumentos más importantes de la propaganda franquista estatal. Ya durante la Guerra Civil Española nació el Departamento Nacional de Cinematografía en el bando nacional y, dentro de este instituto, el Noticiario Español que fue el precedente del NO-DO. El NO-DO, como organismo autónomo, se formó en septiembre de 1942 y el primer noticiario fue proyectado en 1943. Guardó su hegemonía hasta 1956 cuando la Televisión Española comenzó a transmitir sus primeras emisiones continuas. Los noticiarios se presentaban obligatoriamente en los cines antes de las películas, así los espectadores podían enterarse de los sucesos 
nacionales e internacionales más importantes e incluso sobre deporte, cultura y también sobre los acontecimientos de la prensa sensacionalista. Desde luego, el Caudillo también desempeñaba un papel importante en el noticiario. Cuando aparecía en la pantalla, Franco era el protagonista, y de modo similar a los otros sistemas totalitarios, se representaba como un líder paternal, cuidando y trabajando por su nación. Con el paso del tiempo los espectadores conocían mejor su vida privada, es decir, la gente se encontraba con él en el cine (Caparrós Lera, 1999: 67-68; Lénárt, 2018: 133-137).

Una de las características más importantes del NO-DO fue la representación del enemigo más importante dentro de la ideología franquista, el comunismo. En la mayoría de los casos la Unión Soviética se presentó como un monstruo asiático que amenazaba el mundo occidental y cristiano. Siempre había un fuerte contraste entre lo occidental libre, feliz y deseado, y lo oriental miserable y tiránico. Debido a los intentos continuos de desacreditar al comunismo y la URSS, las insurrecciones anticomunistas, así como la revolución húngara de 1956, siempre eran admiradas y apoyadas por el NODO (y mediante ello, por el gobierno español), simpatizando con los patriotas heroicos y condenando el intervencionismo sangriento soviético.

\section{La imagen de la revolución húngara de 1956 en el NO-DO}

\subsection{E1 NO-DO y la revolución}

Aunque la revolución de Hungría prácticamente se terminó el 4 de noviembre de 1956, el noticiario se centra en la revolución húngara y en sus consecuencias sobre todo entre noviembre de 1956 y enero de 1957. Esta diferencia se debe a que el noticiario siempre sigue los acontecimientos con un poco de retraso, ya que necesita tiempo para que las cintas lleguen al país. Durante este período, encontramos trece noticiarios en los que se trata la cuestión húngara. La mayoría de los informes tratan las guerras callejeras y los procesos políticos en Budapest, la situación de los refugiados húngaros y la recepción internacional de la revolución. Por razones de extensión no podemos presentar el contenido de todos los noticiarios, sin embargo, en el cuadro siguiente queremos resumir la información más importante sobre los reportajes sin profundizar en cada grabación (Tabla 1). 
“Hungría mártir" - el noticiario español y la revolución húngara de 1956

\begin{tabular}{|c|c|c|c|c|}
\hline $\begin{array}{c}\mathrm{N}^{\circ} \mathrm{de} \\
\mathrm{NO}-\mathrm{DO}\end{array}$ & Fecha de proyección & Título & Duración & Contenido \\
\hline $722 / \mathrm{A}$ & 5 de noviembre de 1956 & Polonia mártir & $0^{\prime} 45^{\prime \prime}$ & $\begin{array}{l}\text { La opresión soviética en Polonia. } \\
\text { El proceso de Poznań. } \\
\text { Manifestaciones en Hungría y en Polonia. } \\
\text { España como fuerza anticomunista. }\end{array}$ \\
\hline $723 / A$ & 12 de noviembre de 1956 & La tragedia de Hungría & $1^{\prime} 23^{\prime \prime}$ & $\begin{array}{l}\text { La bandera de la que arrancan la estrella roja. } \\
\text { Húngaros en la frontera de Austria. } \\
\text { Manifestación en Polonia. } \\
\text { Manifestación en los Estados Unidos. }\end{array}$ \\
\hline $723 / B$ & 12 de noviembre de 1956 & El sacrificio de Hungría & $1^{\prime} 47^{\prime \prime}$ & $\begin{array}{l}\text { Entierro en un pueblo húngaro tras una descarga } \\
\text { cerrada. } \\
\text { Manifestaciones de estudiantes en Roma y en } \\
\text { Milán. }\end{array}$ \\
\hline $724 / \mathrm{A}$ & 19 de noviembre de 1956 & Hungría mártir & $2^{\prime} 37^{\prime \prime}$ & $\begin{array}{l}\text { Refugiados húngaros en la frontera y en Austria. } \\
\text { La miseria de la revolución. } \\
\text { Manifestación en París. }\end{array}$ \\
\hline $724 / B$ & 19 de noviembre de 1956 & El drama de Hungría & $2^{\prime} 3^{\prime \prime}$ & $\begin{array}{l}\text { Las ruinas de Budapest. } \\
\text { La liberación de Mindszenty. } \\
\text { Misa y manifestación en Madrid. }\end{array}$ \\
\hline $725 / \mathrm{A}$ & 26 de noviembre de 1956 & En la Hungría esclavizada & 4'16" & $\begin{array}{l}\text { Las luchas revolucionarias en Budapest. } \\
\text { Los refugiados en Austria y en la estación de } \\
\text { trenes. } \\
\text { Manifestación en Múnich. } \\
\text { Rueda de prensa del gobierno de Nagy. } \\
\text { La opresión rusa y la vuelta de Kádár. } \\
\text { El mensaje del papa Pío XII. }\end{array}$ \\
\hline $726 / B$ & 3 de diciembre de 1956 & La actualidad en Hungría & $2^{\prime 2} 28^{\prime \prime}$ & $\begin{array}{l}\text { Las dificultades de la huida. } \\
\text { Los refugiados en Austria. }\end{array}$ \\
\hline $727 / A$ & 10 de diciembre de 1956 & Reflejos del mundo & $0^{\prime} 31 "$ & $\begin{array}{l}\text { Eisenhower acoge refugiados húngaros en la Casa } \\
\text { Blanca. }\end{array}$ \\
\hline $728 / \mathrm{A}$ & 17 de diciembre de 1956 & Pro Hungría & $0^{\prime} 52^{\prime \prime}$ & $\begin{array}{l}\text { Festival cinematográfico en Madrid a beneficio de } \\
\text { los húngaros. }\end{array}$ \\
\hline $731 / \mathrm{A}$ & 7 de enero de 1957 & Instantáneas mundiales & 0'34" & $\begin{array}{l}\text { Manifestación en Vietnam por Hungría y contra } \\
\text { el comunismo. }\end{array}$ \\
\hline $731 / \mathrm{B}$ & 7 de enero de 1957 & Refugiados húngaros & $0^{\prime} 52^{\prime \prime}$ & Refugiados húngaros haciendo escala en Madrid. \\
\hline $732 / \mathrm{A}$ & 14 de enero de 1957 & Reflejos del mundo & $02^{\prime \prime}$ & $\begin{array}{l}\text { Visita de Nixon en el centro de refugiados } \\
\text { húngaros en Nueva Jersey. }\end{array}$ \\
\hline $735 / \mathrm{A}$ & 4 de febrero de 1957 & Deportes & $2^{\prime} 41^{\prime \prime}$ & $\begin{array}{l}\text { Partido de fútbol a beneficio de los exiliados } \\
\text { húngaros. }\end{array}$ \\
\hline
\end{tabular}

Tabla 1. Los datos básicos y el contenido de las noticias que tratan el tema de la revolución húngara de 1956

\subsection{Los acontecimientos en Hungría}

A pesar de lo que podríamos pensar (que en la mayoría de las noticias veremos grabaciones que tratarán sobre los disturbios en las calles de Budapest), podemos constatar que en los primeros noticiarios apenas vemos en la pantalla a patriotas, tanques o conflictos armados. Sí que vemos entierros, revolucionarios e insurrectos, pero no 
predominan las imágenes de las guerras callejeras. El noticiario que presenta el mayor número de imágenes sobre los enfrentamientos o disturbios lleva el número 725/A y se estrenó tan solo el 26 de noviembre de 1956 cuando los acontecimientos en la capital húngara ya habían terminado hacía más de tres semanas. De hecho, es la única grabación en la que podemos ver a los revolucionarios que luchan contra las tropas soviéticas, se ven heridos, armas y tanques por las calles de Budapest. Mientras que escuchamos los sonidos de música dramática que acompaña la noticia, se oyen los ruidos de los disparos y de los bombardeos de la ciudad. Aunque en la pantalla vemos la lucha de los húngaros, el narrador nos informa de la idea anticomunista de España, evoca el período de la Guerra Civil, pero no menciona casi nada sobre el combate en la capital húngara.

Otro tema preferido del NO-DO en cuanto a los acontecimientos en el territorio húngaro es el político. En las narraciones se menciona a tres políticos: a Imre Nagy, primer ministro del país en el período revolucionario, al cardenal y arzobispo encarcelado József Mindszenty (él aparece incluso dos veces), y a János Kádár. Los espectadores españoles no se podían enterar detalladamente de la figura de Nagy, salvo que era un comunista titoista. Además, su persona nunca aparece en la pantalla, mientras que de János Kádár se sabía que "fue plegado servilmente a las órdenes del Kremlin". La representación negativa del futuro dictador de Hungría inequívocamente servía para socavar su figura, y, aparte de mantener la mala imagen del bloque soviético, para convencer a los espectadores de que la libertad no estaba presente en estos países títeres. La figura de József Mindszenty fue más interesante para la propaganda española, ya que con su personaje se podía demostrar en el país extraordinariamente católico la situación miserable y esclavizada de la iglesia católica en Hungría y, a través de ello, en los países satélites de la Unión Soviética. Esta representación reforzaba más la imagen bien planeada sobre los enemigos, ya que con la iglesia perseguida tocaba una de las claves de la identidad española que podía provocar resentimiento en muchos. Esta es la explicación por la que aparece en numerosas ocasiones Mindszenty en el noticiario. Del primer reportaje nos enteramos de su liberación de la cárcel tras ocho años de cautiverio y de su discurso en el que acentúa que si las Naciones Unidas no salvan a Hungría, el país solo puede esperar una mayor opresión. Del segundo informe sabemos que debido a la invasión de las tropas soviéticas, el cardenal húngaro tuvo que refugiarse en la embajada de los Estados Unidos en Budapest y su libertad no duró muchos días.

En general podemos afirmar que en cuanto a Hungría y a los acontecimientos, el NO-DO no presenta información concreta sino más bien impresiones generales sobre la situación, intentando ejercer influencia en los espectadores. En numerosas ocasiones encontramos a los parientes, amigos y compañeros llorando o a personas vagabundeando entre los cadáveres, entre las ruinas de las calles de Budapest. Refuerzan el impacto de la destrucción y de la matanza al presentar un funeral (el nombre del lugar no se entiende por la pronunciación inadecuada). Todas estas grabaciones influyen en los sentimientos fundamentales de la gente, convirtiendo los acontecimientos en algo más palpable para el público. 
“Hungría mártir" - el noticiario español y la revolución húngara de 1956

\subsection{La situación de los refugiados}

Uno de los hilos más importantes que aparece en los filmes del NO-DO es la situación de los refugiados. En la mayoría de las grabaciones se trata el tema de los emigrantes húngaros y esta es la cuestión que dura más tiempo en el noticiario, hasta enero de 1957 podemos encontrar reportajes sobre ellos. El NO-DO nos informa tanto de las dificultades de la emigración como de la llegada a los países extranjeros también. Estos reportajes son bastante chocantes y conmovedores incluso hoy.

Entre los emigrantes generalmente vemos los rostros fatigados y agotados de gente sin perspectiva. Siempre aparecen las familias desgarradas, los parientes que lloran despidiéndose y obviamente niños, que casi siempre reaparecen en la pantalla. Podemos constatar que ellos están presentes en la mayoría de las grabaciones. En aquella sociedad española, en aquel contexto ideológico, donde la familia desempeñaba un papel importantísimo, es fácil de entender qué efecto tenían los noticiarios, en especial, si pensamos en las consecuencias de la Guerra Civil Española, cuyas heridas seguían estando presentes en la sociedad y muchos experimentaban algo parecido después de 1939. No obstante, este tipo de representación seguramente no fue consciente por parte de la propaganda, ya que la mayoría de los emigrantes y refugiados españoles fueron los vencidos republicanos a los que trataron como traidores de la patria, es decir, en este caso el NO-DO logra unos objetivos contrarios a sus intenciones.

El noticiario relataba no solo la mísera situación de los refugiados, sino también las circunstancias de la fuga. Vemos que los soviéticos montaron varios puestos de observación y atacaron a los húngaros que debían desafiar las ráfagas de la metralla enemiga que barrían la zona por donde habían de pasar los emigrantes. Además, para evitar todas las posibilidades de fuga, los rusos volaron los puentes, así que los refugiados debían utilizar unos troncos de árboles para cruzar los ríos. Estos reportajes debían despertar la compasión y la solidaridad en los espectadores españoles, incluso en los espectadores de hoy.

El NO-DO siguió la fortuna de los emigrantes incluso en el extranjero. Informa de la situación en Austria, donde establecieron campos para los refugiados y la Cruz Roja les abastecía de alimentos, ropa y medicamentos. Incluso dice que más de ochenta y dos mil refugiados dejaron Hungría. Los Estados Unidos también aparecen en esta situación. Debido a las circunstancias internacionales, se presentó a EE.UU., como aliado cada vez más importante, como defensor de la libertad. En la pantalla aparece el presidente Eisenhower, mientras acoge a unas familias húngaras en la Casa Blanca en Washington, y también vemos al vicepresidente Nixon que visitó a los húngaros en un campo de refugiados en Nueva Jersey. España tampoco se queda atrás. Cuando vemos a unos húngaros que hacen escala en Madrid al viajar a Argentina, Ferenc Marosy los acoge en el aeropuerto de la capital y mediante estas imágenes los espectadores podían asegurarse de que ellos estaban en el bando bueno, en el mundo libre para los que huyen de la tiranía de Europa Oriental (pese a que en la España dictatorial también 
faltaban muchos valores de libertad, pero, por lo menos, el país podía transmitir así esta imagen de sí mismo hacia sus ciudadanos).

\subsection{La recepción internacional de la revolución}

El tema más profundamente tratado del noticiario sobre la revolución húngara fue su recepción internacional y nacional, es decir, la española. Daban información de varios países y continentes, pero EE.UU. desempeñaba un papel dominante. Prácticamente en todos los noticiarios aparece de algún modo el extranjero o la voz española sobre la insurrección.

En Europa generalmente se enteraron de los acontecimientos húngaros mediante los países vecinos o los países que tenían las raíces culturales e históricamente parecidas a las de España, es decir, Francia, Italia y el Vaticano. En Italia podemos ver cómo estudiantes de Roma y Milán organizaron manifestaciones de solidaridad por Hungría en las ciudades que dentro de poco desembocarían en disturbios violentos contra la policía. En la capital francesa también hubo atrocidades cuando, tras una manifestación pacífica, la masa rabiada atacó la sede del partido comunista de Francia, haciendo arder periódicos en sus manos. Un momento interesante del noticiario es cuando presentan a un grupo de alemanes en Múnich que conmemoraban la revolución y a los caídos húngaros lanzando una corona fúnebre en el Danubio para que esa llegara flotando a Budapest. El Papa y el Vaticano también desempeñaban un papel importante en la recepción internacional de la revolución, ya que la Santa Sede, por su ideología fuertemente católica, servía como brújula moral para los españoles. Las palabras de Pío XII se citan incluso dos veces, primero por su dolor por la sangre derramada y por violar las leyes y los derechos humanos, y después comparten información sobre su discurso político transmitido en la radio.

La grabación más curiosa que ataña a la revolución húngara viene de Asia. En Vietnam, en el país asiático dividido, una multitud de mujeres anticomunistas, vestidas de blanco, expresan su dolor y su solidaridad hacia todos los que se alzaban contra la tiranía soviética, sobre todo hacia los húngaros. Las participantes de la manifestación enviaron una resolución a las Naciones Unidas, condenando la opresión y la tiranía de la URSS.

Obviamente, Estados Unidos es una de las figuras claves en la representación de la recepción de la revolución. Este país está presente ya en la primera noticia que trata sobre la revolución húngara. Se puede ver la manifestación de los estadounidenses en Washington y en Nueva York, en la sede de las Naciones Unidas, a favor de los húngaros. Sin embargo, tras estos movimientos de simpatía, Estados Unidos está presente sobre todo por su intención de ayudar a los refugiados. La representación del estado americano como la tierra de la libertad, la democracia y la paz tenía el objetivo de reforzar esta imagen cada vez más amistosa sobre los EE.UU. por la mejora de las 
relaciones internacionales entre los dos países. El país acogedor e igualitario y sus políticos siempre aparecen como unos salvadores del mundo bipolar.

Desde luego, España también aparece en el noticiario. Nos enteramos de que Alberto Martín Artajo, Ministro de Exteriores, fue uno de los primeros en la Asamblea General de las Naciones Unidas que protestó por Hungría. Aparte de los pasos diplomáticos, en Madrid organizaron protestas, misas por Hungría e incluso organizaron un festival de cine en Madrid, haciendo una colecta para las familias de las víctimas y para los refugiados. En un noticiario de febrero también nos informan de que en Madrid se organizó un partido de fútbol benéfico entre España y Holanda con el protagonismo del jugador del Barcelona, László Kubala. Todos estos pasos reforzaban más la solidaridad en los espectadores que puede que no supieran nada de los intentos de Franco en enviar tropas españolas a Hungría. Todos estos gestos, todas estas grabaciones servían para consolidar la imagen anticomunista de España y para justificar que el país ibérico fue uno de los líderes en la lucha anticomunista. De esta contienda falta solo una persona: Francisco Franco, el Caudillo, que no aparece ni en una imagen de las cintas en las noticias referentes a la revolución húngara lo que pudo dejar la impresión de carencia en los espectadores.

\section{Conclusiones}

La revolución húngara de 1956 encajaba muy bien en la propaganda española por su carácter anticomunista que el NO-DO aprovechaba al máximo y con mucha eficacia. Basta pensar en la película de Rapsodia de sangre, dirigida por Antonio Isasi-Isasmendi en 1957, que -según las memorias del realizador- se inspiró en las imágenes del noticiario. Además, en la película podemos ver algunos fragmentos originales de las grabaciones del NO-DO (Lénárt, 2014: 104), por lo que su impacto en la sociedad española es indiscutible. Aunque en la pantalla podemos ver imágenes sobre Hungría, la revolución y los refugiados, tenemos que constatar que en el foco de los reportajes no estaban los acontecimientos de Budapest o de Hungría. Los espectadores no se enteraban de los sucesos decisivos y cruciales de la revolución. En el NO-DO dominan, sobre todo, los temas más relevantes y más fáciles de entender o de identificarse para España y la narración cambia el significado de las imágenes: lo importante es deshonrar el comunismo y profesar el papel clave de España en la lucha anticomunista. Todo eso hizo posible que la propaganda franquista explotara la revolución a favor del gobierno y de la dictadura, y que justificara y reforzara su imagen anticomunista y su rol en el mundo bipolar. Además, demostró sus méritos después de una crisis interna, pero no quiso transmitir una imagen objetiva y detallada sobre la revolución - lo que ni siquiera intentó ocultar. 


\section{Referencias bibliográficas}

Anderle, Ádám (2009). Hungría y España, relaciones milenarias. Szeged: Szegedi Egyetemi Kiadó.

Anderle, Ádám (2002). Spanyolország története. Szeged: Pannonica Kiadó.

Caparrós Lera, José María (1999). Historia crítica del cine español (Desde 1897 hasta hoy). Barcelona: Editorial Ariel.

Eiroa San Francisco, Matilde (2007). Relaciones internacionales y estrategias de comunicación de la España de Franco ante la coyuntura de 1956. Revista Historia y Comunicación Social, 12. 5-22.

Eiroa San Francisco, Matilde (2001). Las relaciones de Franco con Europa Centro-Oriental (1939-1955). Barcelona: Editorial Ariel.

Ferrero Blanco, María Dolores (2002). La revolución búngara de 1956. El despertar democrático de Europa del Este. Huelva: Universidad de Huelva.

Lénárt, András (2018). A spanyol film a Franco-diktatúrában. Ideológia, propaganda és filmpolitika. Szeged: JATEPress.

Lénárt, András (2014). La imagen de Hungría en el cine franquista. Acta Hispanica, 19. 1-111.

Martínez, Jesús A. (1999). La consolidación de la dictadura (1951-1959). En: Martínez, Jesús A. (coord.). Historia de España. Siglo XX. 1939-1996. Madrid: Ediciones Cátedra. 71-130.

Romsics, Ignác (2005). Magyarország története a XX. században. Budapest: Osiris Kiadó.

Ramón, Tamames (1988). Historia de España. La República. La era de Franco. Madrid: Alianza Editorial.

Tranche, Rafael R. - Sánchez-Biosca, Vicente (2006). NO-DO. El tiempo y la memoria. Madrid: Cátedra/Filmoteca Española.

Virányi, Péter (2019). A propaganda természete. Jel-Kép, 3. 2-16.

Zalai, Anita (2017). Franco és az 1956-os magyar forradalom. Belvedere Meridionale, 1. 102-111.

Zeidler, Miklós (2012). Kultusz és propaganda. En: Ballabás, Dániel (ed.). Kultusz és propaganda. Eger: Líceum Kiadó. 7-17.

\section{Fuentes}

NO-DO 722/A - POLONIA MÁRTIR (5 de noviembre de 1956) - 00:02:26 - 00:03:11, 0'45" Asequible en: https://www.rtve.es/filmoteca/no-do/not-722/1487238/, fecha de consulta: 25-10-2020. 
“Hungría mártir" - el noticiario español y la revolución húngara de 1956

NO-DO 723/A - LA TRAGEDIA DE HUNGRÍA (12 de noviembre de 1956) 00:08:47 - 00:10:10, 1'23" Asequible en: https://www.rtve.es/filmoteca/no-do/not723/1487234, fecha de consulta: 25-10-2020.

NO-DO 723/B - EL SACRIFICIO DE HUNGRÍA (12 de noviembre de 1956) 00:08:14 - 00:10:01, 1'47' Asequible en: https://www.rtve.es/filmoteca/no-do/not723/1487235/, fecha de consulta: 25-10-2020.

NO-DO 724/A - HUNGRÍA MÁRTIR (19 de noviembre de 1956) - 00:07:44 00:10:21, 2’37’ Asequible en: https://www.rtve.es/filmoteca/no-do/not-724/1487236/, fecha de consulta: 25-10-2020.

NO-DO 724/B - EL DRAMA DE HUNGRÍA (19 de noviembre de 1956) - 00:07:59 00:10:02, 2'3" Asequible en: https://www.rtve.es/filmoteca/no-do/not-724/1487237/, fecha de consulta: 25-10-2020.

NO-DO 725/A - EN LA HUNGRÍA ESCLAVIZADA (26 de noviembre de 1956) 00:06:30 - 00:10:46, 4'16" Asequible en: https://www.rtve.es/filmoteca/no-do/not725/1487241/, fecha de consulta: 25-10-2020.

NO-DO 726/B - LA ACTUALIDAD EN HUNGRÍA (3 de diciembre de 1956) 00:07:41 - 00:10:09, 2’28' Asequible en: https://www.rtve.es/filmoteca/no-do/not726/1487052/, fecha de consulta: 25-10-2020.

NO-DO 727/A - REFLEJOS DEL MUNDO (10 de diciembre de 1956) 00:01:59 00:02:30, 0’31" Asequible en: https://www.rtve.es/filmoteca/no-do/not-727/1487049/, fecha de consulta: 25-10-2020.

NO-DO 728/A - PRO HUNGRÍA (17 de diciembre de 1956) 00:00:38 - 00:01:30, 0'52" Asequible en: https://www.rtve.es/filmoteca/no-do/not-728/1487057/, fecha de consulta: 25-10-2020.

NO-DO 731/A - INSTANTANEAS MUNDIALES (7 de enero de 1957) 00:03:10 00:03:44, 0’34" Asequible en: https://www.rtve.es/filmoteca/no-do/not-731/1486270/, fecha de consulta: 25-10-2020.

NO-DO 731/B - REFUGIADOS HÚNGAROS (7 de enero de 1957) 00:00:31 00:01:23, 0’52" Asequible en: https://www.rtve.es/filmoteca/no-do/not-731/1486271/, fecha de consulta: 25-10-2020.

NO-DO 732/A - REFLEJOS DEL MUNDO (14 de enero de 1957) 00:01:51 00:02:23, 0’32” Asequible en: https://www.rtve.es/filmoteca/no-do/not-732/1486272/, fecha de consulta: 25-10-2020.

NO-DO 735/A - DEPORTES (4 de febrero de 1957) 00:07:46 - 00:10:27, 2'41' Asequible en: https://www.rtve.es/filmoteca/no-do/not-735/1486636/, fecha de consulta: 25-10-2020. 